\title{
Sternoclavicular joint infection caused by Coxiella burnetii: a case report
}

\author{
Emmanouil Angelakis ${ }^{*}$, Simon-Djamel Thiberville ${ }^{2,3}$, Matthieu Million ${ }^{1}$ and Didier Raoult ${ }^{1}$
}

\begin{abstract}
Background: Few cases of Q fever osteoarticular infection have been reported, with chronic osteomyelitis as the most common manifestation of Q fever osteoarticular infection. Here we present the case of a sternoclavicular joint infection caused by Coxiella burnetii and localized by positron emission tomography scanning.

Case presentation: A 67-year-old French man from south France was hospitalized for fever and confusion. An examination revealed subclavicular and axillary lymph node enlargement. Computed tomography scanning and transesophageal echocardiogram were normal, and magnetic resonance imaging scanning did not reveal signs of infection. An immunofluorescence assay of an acute serum sample was positive for $C$. burnetii and he was treated with $200 \mathrm{mg}$ doxycycline for 21 days. An immunofluorescence assay of convalescent serum sampled after 2 months revealed very high $C$. burnetii antibody titers. To localize the site of the infection, we performed positron emission tomography scanning, which revealed intense fluorodeoxyglucose uptake in his right sternoclavicular joint; treatment with $200 \mathrm{mg}$ oral doxycycline daily and $200 \mathrm{mg}$ oral hydroxychloroquine three times daily for 18 months was initiated.
\end{abstract}

Conclusions: Q fever articular infections may be undiagnosed, and we strongly urge the use of positron emission tomography scanning in patients with high C. burnetii antibody titers to localize the site of $C$. burnetii infection.

Keywords: Coxiella burnetii, Q fever, Osteoarticular infection, Case report, Sternoclavicular joint infection

\section{Background}

Q fever is a potentially life-threatening worldwide zoonosis caused by an obligate intracellular bacterium, Coxiella burnetii [1]. Infective endocarditis is the most frequent $\mathrm{Q}$ fever chronic infection, followed by vascular, osteoarticular, hepatitis and pulmonary infection [1]. To date, few cases of $\mathrm{Q}$ fever osteoarticular infection have been reported in the literature; they include osteomyelitis, spondylodiscitis and two cases of tenosynovitis [2, 3]. In fact, only seven (2\%) osteoarticular infections were detected in a large serologic study which included more than 1300 cases of Q fever that extended over 14 years [4], and $11(0.7 \%)$ cases in a recent 7 -year study which included more than 1400 cases [5]. Osteomyelitis is the most common manifestation of $\mathrm{Q}$ fever osteoarticular infection, followed by vertebral spondylodiscitis and paravertebral abscess $[1,2]$. C. burnetii has also

\footnotetext{
* Correspondence: e.angelakis@hotmail.com

'URMITE, UM63, CNRS 7278, IRD 198, Inserm 1095, Aix-Marseille Université,

13005 Marseille, France

Full list of author information is available at the end of the article
}

been implicated in a prosthetic joint infection [3], while two cases of tenosynovitis have been reported [6].

Q fever osteoarticular infection can easily go undiagnosed because of the long evolution of articular involvement, which is accompanied by a low level of laboratory and inflammatory signs [1]. However, in recent years, positron emission tomography (PET) scanning has been successfully used for the identification of infectious foci in C. burnetii infections [1, 7], and the use of PET scanning was recently proposed as a complementary tool for patients with high $C$. burnetii antibody titers in order to localize the site of $C$. burnetii infection [1, 8]. Here we present a case of a sternoclavicular joint infection caused by $C$. burnetii, localized by PET scanning.

\section{Case presentation}

A 67-year-old French man from south France was admitted to our hospital approximately 1 year ago (February 2015) with fever $\left(39^{\circ} \mathrm{C}\right)$ and confusion. He mentioned increased alcohol consumption. An examination revealed 
subclavicular and axillary lymph node enlargement. Moreover, he presented cerebellar ataxia, with loss of equilibrium and difficulty walking. Laboratory values revealed elevated C-reactive protein $(216 \mathrm{mg} / \mathrm{L})$ and liver enzyme levels (aspartate aminotransferase $100 \mathrm{IU} / \mathrm{L}$, alanine aminotransferase $69 \mathrm{IU} / \mathrm{L}$, gamma-glutamyl transferase $125 \mathrm{IU} / \mathrm{L}$ ) and hyponatremia (sodium $123 \mathrm{mEq} / \mathrm{L}$ ). A liver ultrasound showed hepatomegaly. Computed tomography (CT) scanning was normal and magnetic resonance imaging (MRI) scanning did not reveal signs of infection. Treatment with ceftriaxone and levofloxacin was introduced, but his fever did not resolve. A serum sample was sent to our laboratory in Marseille and an immunofluorescence assay (IFA) was positive for $C$. burnetii; phase I titers for immunoglobulin (Ig) G, IgM, and IgA were 400, 200 and 0, respectively, and phase II titers were 400, 200, and 0, respectively. The diagnosis of acute $\mathrm{Q}$ fever infection was made and he was treated with $200 \mathrm{mg}$ oral doxycycline daily for 21 days. IgG anticardiolipin (aCL) antibody levels in the serum sample were very high (216 GPLU), and we suspected valvular heart disease and a possible progression to $\mathrm{Q}$ fever endocarditis [5]. However, a transesophageal echocardiogram was normal. After 2 months we obtained a second serum sample and phase I IFA titers for IgG, IgM, and IgA were 25,600, 0 and 0 , respectively, and phase II titers were 25,600, 0, and 0, respectively. Both serum samples were negative for $C$. burnetii by quantitative polymerase chain reaction (qPCR) for the IS1111 and the IS30A spacers [9]. A localized C. burnetii infection was suspected; lymph node biopsies were performed that were negative for $C$. burnetii by molecular assays. For each sample, we verified the quality of DNA handling and extraction of samples by qPCR for a housekeeping gene encoding beta-actin [10]. The lymph node biopsies were also negative for $C$. burnetii by immunohistochemical analysis using a monoclonal antibody against $C$. burnetii with an immunoperoxidase kit [11]. Moreover, the lymph nodes were also tested by fluorescent in situ hybridization (FISH) [12], which was also negative. To localize the site of the infection we performed PET scanning, which revealed intense fluorodeoxyglucose uptake in his right sternoclavicular joint (Fig. 1). A diagnosis of sternoclavicular joint infection by C. burnetii was made, and treatment with $200 \mathrm{mg}$ oral doxycycline daily and $200 \mathrm{mg}$ oral hydroxychloroquine three times daily for 18 months was introduced. After 6 months follow-up, the outcome was favorable, with a four-fold decrease in the phase I and phase II IFA titers for IgG.

\section{Discussion}

We report a case of Q fever sternoclavicular joint infection diagnosed through serology and localized using PET scanning. PET scanning has been previously used for the identification of infectious foci in C. burnetii vascular infections [7], in the bone marrow [13], in the liver [14], and recently two cases of arthritis and subacromial bursitis caused by $C$. burnetii were also localized [1]. In this case we suspected a localized C. burnetii infection because of the very high IFA titers and IgG-aCL levels [15]. In fact, persistent localized infections have been associated with increased levels of IgG and IgA antibodies [16]. However, echocardiography did not reveal signs of endocarditis and lymph nodes were negative for $C$. burnetii. As $\mathrm{Q}$ fever articular infections
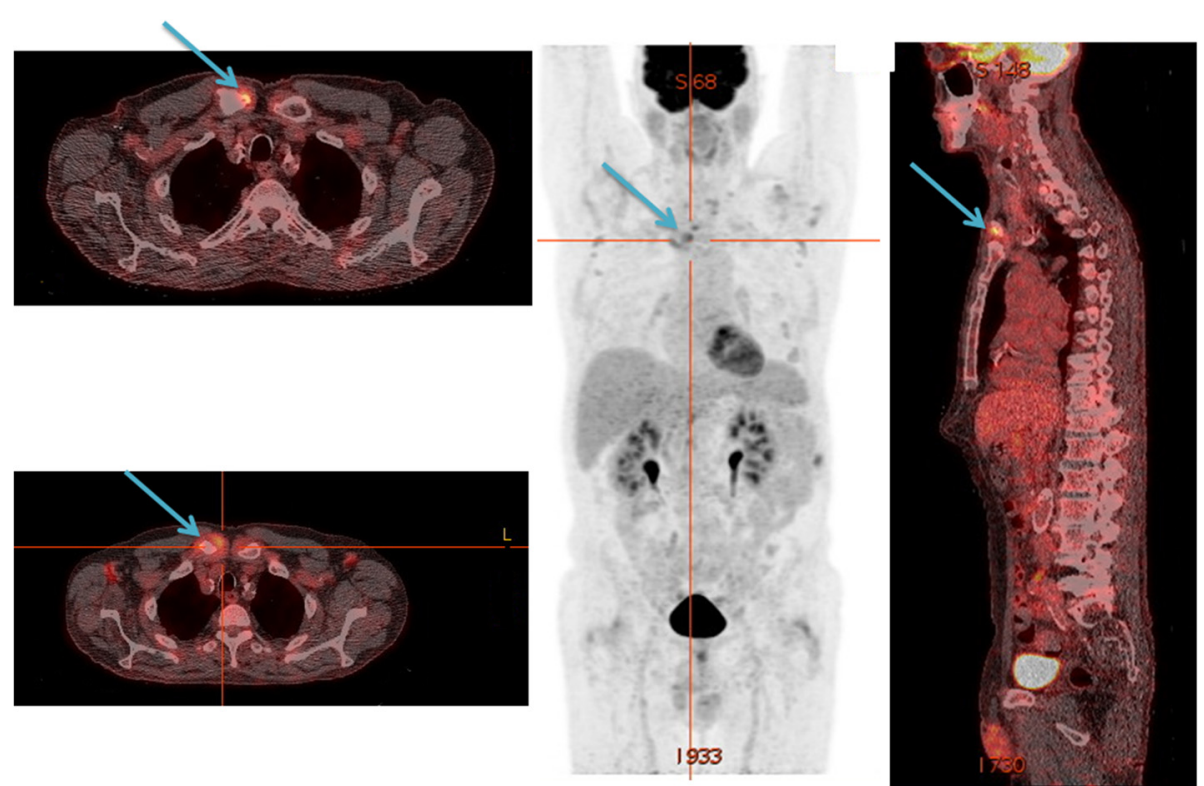

Fig. $1{ }^{18}$ F-fluorodeoxyglucose positron emission tomography computed tomography in a patient with Coxiella burnetii sternoclavicular joint infection. The high fluorodeoxyglucose uptake (arrows) is observed at the level of the sternoclavicular joint 
present a long evolution of articular involvement, accompanied by a low level of inflammatory signs, and can easily remain undiagnosed [2], the PET scanner was a valuable tool for the identification and the localization of the infectious foci of C. burnetii in the sternoclavicular joint. Although we did not test the sternoclavicular joint to confirm the diagnosis, a localized infection with $C$. burnetii is associated with high antibody titers against $C$. burnetii [17]. For our patient the only fluorodeoxyglucose uptake was in the right sternoclavicular joint indicating that this was the site of fixation.

Epidemiological patterns of $\mathrm{Q}$ fever osteoarticular infections may consist of sporadic cases that are difficult to diagnose. As with the majority of $\mathrm{Q}$ fever osteoarticular infections, our patient was an adult man more than 50-years old [2]. Although most described cases with osteoarticular infections present swelling and arthralgia without inflammatory signs $[2,6]$, our patient did not complain of arthralgia. Despite limited data concerning therapeutic strategies for Q fever osteoarticular infections, a regimen of doxycycline and hydroxychloroquine for 18 months has been suggested [1, 2]. Our patient was treated with a course of doxycycline and hydroxychloroquine for 18 months.

\section{Conclusion}

In conclusion, we confirm the efficacy of PET scanning for the identification of infectious foci in C. burnetii infections and we strongly urge its use in patients with high C. burnetii antibody titers in order to localize the site of the C. burnetii infection.

\section{Abbreviations}

$\mathrm{aCL}$, anticardiolipin; $\mathrm{CT}$, computed tomography; FISH, fluorescent in situ hybridization; IFA, immunofluorescence assay; Ig, immunoglobulin; MRI, magnetic resonance imaging; PET, positron emission tomography; $\mathrm{PPCR}$, quantitative polymerase chain reaction.

\section{Acknowledgements}

None.

\section{Authors' contributions}

EA wrote this manuscript and followed-up the patient; SDT conceived of the case report; MM and DR followed-up the patient. All authors read and approved the final manuscript.

\section{Competing interests}

The authors declare that they have no competing interests.

\section{Consent}

Written informed consent was obtained from the patient for publication of this case report and any accompanying images. A copy of the written consent is available for review by the Editor-in-Chief of this journal.

\section{Author details}

'URMITE, UM63, CNRS 7278, IRD 198, Inserm 1095, Aix-Marseille Université, 13005 Marseille, France. ${ }^{2}$ UMR190, Aix-Marseille Université / IRD / EHESP French School of Public Health, Marseille, France. ${ }^{3}$ Hospital Louis Raffalli, Medicine D Unit, Infectious Disease and Internal Medicine, Manosque, France.
Received: 14 March 2016 Accepted: 11 May 2016

Published online: 31 May 2016

\section{References}

1. Angelakis E, Edouard S, Lafranchi MA, Pham T, Lafforgue P, Raoult D. Emergence of Q fever arthritis in France. J Clin Microbiol. 2014;52:1064-7.

2. Merhej V, Tattevin P, Revest M, Le Touvet B, Raoult D. Q fever osteomyelitis: a case report and literature review. Comp Immunol Microbiol Infect Dis. 2012;35:169-72.

3. Tande AJ, Cunningham SA, Raoult D, Sim FH, Berbari EF, Patel R. A case of $\mathrm{Q}$ fever prosthetic joint infection and description of an assay for detection of Coxiella burnetii. J Clin Microbiol. 2013;51:66-9.

4. Raoult D, Tissot-Dupont H, Foucault C, Gouvernet J, Fournier PE, Bernit E, et al. Q fever 1985-1998 - Clinical and epidemiologic features of 1,383 infections. Medicine. 2000:79:109-23.

5. Million M, Thuny F, Bardin N, Angelakis E, Edouard S, Bessis S, et al. Antiphospholipid antibody syndrome with valvular vegetations in acute $Q$ fever. Clin Infect Dis. 2015;62:537-44.

6. Landais C, Fenollar F, Constantin A, Cazorla C, Guilyardi C, Lepidi H, et al. Q fever osteoarticular infection: four new cases and a review of the literature. Eur J Clin Microbiol Infect Dis. 2007;26:341-7.

7. Van Assen S, Houwerzijl EJ, van den Dungen JJ, Koopmans KP. Vascular graft infection due to chronic $Q$ fever diagnosed with fusion positron emission tomography/computed tomography. J Vasc Surg. 2007;46:372.

8. Barten DG, Delsing CE, Keijmel SP, Sprong T, Timmermans J, Oyen WJ, et al. Localizing chronic Q fever: a challenging query. BMC Infect Dis. 2013:13:413.

9. Angelakis E, Million M, D'Amato F, Rouli L, Richet $H$, Stein A, et al. Q fever and pregnancy: disease, prevention, and strain specificity. Eur J Clin Microbiol Infect Dis. 2012;32:361-8.

10. Eldin C, Angelakis E, Renvoise A, Raoult D. Coxiella burnetii DNA, but not viable bacteria, in dairy products in France. Am J Trop Med Hyg. 2013:88:765-9.

11. Lepidi $\mathrm{H}$, Gouriet F, Raoult D. Immunohistochemical detection of Coxiella burnetii in chronic Q fever hepatitis. Clin Microbiol Infect. 2009;15 Suppl 2:169-70.

12. Melenotte C, Million M, Audoly G, Gorse A, Dutronc H, Roland G, et al. B-cell non-Hodgkin lymphoma linked to Coxiella burnetii. Blood. 2015;127:113-21.

13. Alwis $L$, Balan $K$, Wright $P$, Lever $A$, Carmichael $A$. Bone marrow involvement in Q fever - detection by fluorine-18-labelled fluorodeoxyglucose PET. Lancet Infect Dis. 2009;9:718.

14. Dugdale C, Chow B, Yakirevich E, Kojic E, Knoll B. Prolonged pyrexia and hepatitis: Q fever. Am J Med. 2014;127:928-30.

15. Million $M$, Walter $G$, Bardin $N$, Camoin $L$, Giorgi R, Bongrand $P$, et al. Immunoglobulin $\mathrm{G}$ anticardiolipin antibodies and progression to $\mathrm{Q}$ fever endocarditis. Clin Infect Dis. 2013;57:57-64.

16. Million M, Thuny F, Richet $\mathrm{H}$, Raoult D. Long-term outcome of $\mathrm{Q}$ fever endocarditis: a 26-year personal survey. Lancet Infect Dis. 2010;10:527-35.

17. Raoult D. Chronic Q, fever: expert opinion versus literature analysis and consensus. J Infect. 2012;65:102-8.
Submit your next manuscript to BioMed Central and we will help you at every step:

- We accept pre-submission inquiries

- Our selector tool helps you to find the most relevant journal

- We provide round the clock customer support

- Convenient online submission

- Thorough peer review

- Inclusion in PubMed and all major indexing services

- Maximum visibility for your research

Submit your manuscript at www.biomedcentral.com/submit
Biomed Central 